\title{
Sistema de revisão por pares na ciência: o caso de revistas científicas do Brasil, da Espanha e do México
}

\author{
Cláudio N. N. Silva, Murilo A. A. Silveira \& Suzana P. M. Mueller \\ Inst. Federal de Brasília / Univ. Federal de Pernambuco / Univ. de Brasília \\ E-mail: claudio.silva@ifb.edu.br/muriloas@gmail.com / \\ suzanapmmegmail.com
}

\begin{abstract}
Resumo
Apresenta as modalidades de revisão por pares praticadas por periódicos científicos mais qualificados no Brasil, na Espanha e no México. Discute essas modalidades, com ênfase em quatro áreas do conhecimento: Ciências da Vida, Ciências Puras, Ciências Sociais e Humanidades. De caráter exploratório, a pesquisa utilizou-se da opinião dos editores dos periódicos dos três países contemplados sobre as práticas avaliativas conduzi-

das na revisão de originais. Os principais resultados são: a) práticas de avaliação semelhantes entre os periódicos científicos dos três países pelas quatro áreas do conhecimento; e b) práticas de avaliação plurais nas Ciências Puras em relação aos países investigados. Conclui que as modalidades de revisão por pares são regulares e semelhantes nos três países, mas sinalizam sensíveis diferenças quando se referem às áreas do conhecimento.
\end{abstract}

Palavras-chave: Periódicos científicos; revisão por pares; Brasil; Espanha; México.

\begin{abstract}
It presents the modalities of peer review practiced by the most qualified scientific journals in Brazil, Spain and Mexico. It discusses these methods, focusing on four areas of knowledge: Life Sciences, Pure Sciences, Social Sciences and Humanities. The research, exploratory, analyzed opinions of these high ranked journals produced in each of the three countries, focusing on evaluation practi-

ces of submitted papers. Main results are: a) the four subject areas hold similar evaluation practices in the three countries. b) Considering the four areas, Pure Sciences present the most varied practices, despite the country. It concludes that peer review modalities are regularly practiced and are similar in the three countries, but indicates significant differences among areas of knowledge.
\end{abstract}


Keywords: Scientific journals; peer review; Brazil; Spain; Mexico.

\section{Introdução}

To domínio da Comunicação Científica, os estudos sobre avaliação de re1 vistas científicas compreendem múltiplas possibilidades de investigação, destacando-se o processo de revisão pelos pares como uma das vertentes. Tal perspectiva evidencia a relação entre os integrantes, as posições que exercem e as decisões que tomam, formatando o fluxo concernente às atividades que compõem o processo. Do momento da submissão até à publicação (ou rejeição), autores, revisores e editores realizam suas funções editoriais com base em preceitos e normas de conduta, assim como em noções de conhecimento que constituem a dinâmica do campo científico (Stumpf, 2005). O panorama descrito se insere, deste modo, na lógica da cadeia produtiva do conhecimento científico, sustentado por estes atores científicos que estabelecem a configuração da revisão pelos pares como um sistema.

A literatura especializada define três sistemas de revisão por pares (peer review) na ciência: duplo cego, simples cego e aberto. O sistema duplo cego (double blind peer review) é caracterizado pelo anonimato entre autores e revisores. O sistema simples cego (single blind peer review) é aquele em que autores são conhecidos dos revisores, mas revisores permanecem anônimos para os autores. E, por fim, o sistema aberto (open peer review) é aquele em que tanto autores quanto revisores conhecem a identidade um do outro (Pavan; Stumpf, 2009). As autoras também enfatizam que a determinação para a escolha do sistema de revisão por pares varia de acordo com as formas de disseminação do conhecimento legitimado pelos campos científicos.

A amplitude de possibilidades para estudo do sistema de revisão por pares em periódicos científicos é desafiante, na medida em que aspectos psicológicos, sociológicos, políticos, históricos e éticos, isolados ou conjuntamente, influenciam as atividades de avaliação e as formas de divulgação nas ciências. Desses aspectos decorrem a homogeneização e cristalização das práticas avaliativas nos níveis institucionais, geográficos e temáticos em âmbito local, regional, nacional e internacional. Contudo, admite-se que tais imperativos sinalizam o consenso acordado entre os praticantes da ciência em um dado 
Sistema de revisão por pares na ciência: o caso de revistas científicas do

momento histórico e circunscrito em um espaço em que as variadas relações se conformam (Bufrem, 2014).

Diante do exposto, chega-se às seguintes questões de pesquisa: a) como se configura o sistema de revisão pelos pares nas revistas científicas por áreas do conhecimento no Brasil, na Espanha e no México?; b) qual o sistema de revisão pelos pares preferencial dos periódicos científicos dessas áreas em cada país?; e c) as áreas do conhecimento em cada país se comportam de forma semelhante no que se refere à adoção do sistema de avaliação da literatura periódica?

Para responder tais questionamentos, o objetivo central do trabalho é examinar os sistemas de avaliação pelos pares adotados pelas principais revistas brasileiras, mexicanas e espanholas das várias áreas do conhecimento com o objetivo de identificar diferenças e semelhanças em suas práticas de avaliação.

O entendimento que norteia o estudo é de que, por proximidade de objetos e objetivos, as áreas do conhecimento aglutinam campos e domínios específicos com múltiplos fins. A tônica da aproximação aqui admitida se dá pelo compartilhamento de ideias, conceitos, atividades, instrumentos de controle e divulgação, entre outros, de forma espontânea ou induzida (Souza, 2004). Logo, visualizar às formas de avaliação que governam a prática científica das áreas permite compreender como funciona a lógica de produção do conhecimento por meio das revistas científicas.

\section{A revisão por pares: aspectos gerais}

Um pesquisador que precisa ter seus trabalhos publicados deve submeter sua produção à avaliação de outros pesquisadores que, como ele, é também conhecedor (ainda que não necessariamente em profundidade) do objeto pesquisado. Desde o Século XVII, este mecanismo de avaliação é utilizado nas publicações científicas e recebe o nome de revisão por pares (Brown, 2006; Cassella, 2010; Jenal et alli, 2012; Ranalli, 2011). Depois de realizar seu trabalho de investigação, sozinho ou em equipe, empírico ou teórico, "os cientistas apresentam suas conclusões de pesquisa a um periódico científico, e este, por sua vez, as envia para serem avaliadas em termos de qualidade, importância e originalidade a peritos qualificados e independentes que estão pesquisando e publicando trabalhos no mesmo campo (pares)" (Brown, 2004, p. ix). 
Segundo o Science Media Centre, em um pequeno guia que traz orientações sobre a revisão por pares, esse processo significa: a) uma forma de controle de qualidade científica; uma forma de autorregulação para a ciência; um processo de verificação, crítica e melhoria da pesquisa. O guia também afirma que "a revisão por pares é onde os cientistas abrem sua investigação ao escrutínio de outros especialistas no campo"(SMC, 2003, p. 1). Para ilustrar como se processa a revisão por pares, traz-se à discussão a Figura 1 que ilustra a trajetória avaliativa nas revistas científicas.

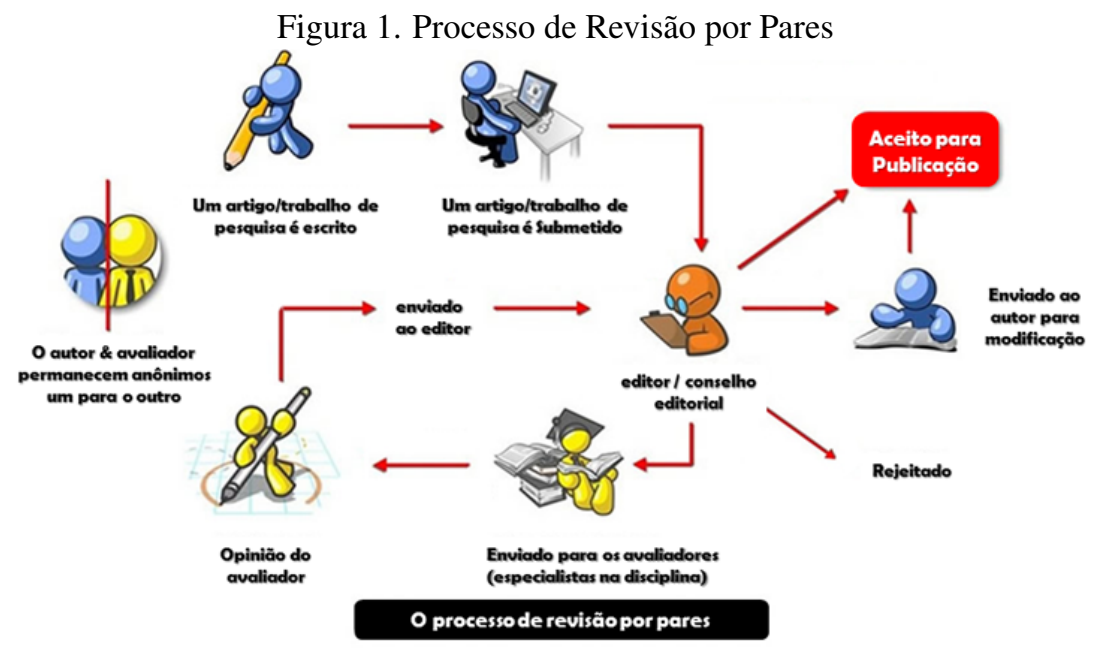

Fonte: www.enago.com.br

O fluxo avaliativo referente ao processo de revisão por pares também é alvo de críticas, mesmo considerando-o como mecanismo de controle da qualidade da produção científica enquanto instância privilegiada da comunicação científica, especialmente em periódicos. As críticas mais recorrentes apontam para a natureza subjetiva desse processo, sua incapacidade de detectar erros, falsificação e plágio; a lentidão e o atraso na publicação do artigo; subjetividade e parcialidade do parecer do revisor e também e possíveis conflitos de interesse nesse processo (Bortomé, 2010; Cassella, 2010).

As críticas empreendidas ao sistema de avaliação são legítimas, mas também não se deve desconsiderar os seus benefícios, sobretudo quando o processo é conduzido por cientistas comprometidos com a ciência. Desta forma, 
Sistema de revisão por pares na ciência: o caso de revistas científicas do

pondera-se: poderia a ciência lograr outra forma de aferir os méritos e a importância do trabalho de seus agentes que não recorrer aos próprios agentes, verdadeiros conhecedores dos protocolos científicos que não estão presentes em outros campos sociais? Para Stumpf (2005), o sistema de revisão pelos pares possui fragilidades de diversas ordens, porém ele é o mais difundido e tradicional. Destaca ainda que as críticas devem ser feitas, mas com apresentação de soluções aos pontos que necessitam de melhorias e aprimoramento.

Um dos pontos cruciais que circunda as formas de revisão por pares recai no anonimato, tanto de autores quanto de revisores. É difícil precisar se os méritos do anonimato superam os deméritos. Segundo Ohler (2010), em periódicos de enfermagem mais de $90 \%$ dos revisores preferem este sistema e acreditam que ele contribui mais para a qualidade do processo. O revisor parece mais interessado no anonimato do que o autor, pois dependendo do resultado da avaliação, o revisor não terá problemas com autor, que não poderá identificá-lo. Mulligan, Hall e Raphael (2013), em uma pesquisa com mais de 4 mil respondentes, identificaram que a modalidade de revisão mais indicada pelos respondentes como eficaz foi o duplo cego (76\%), seguido do simples cego (45\%) e do sistema aberto (20\%).

A base de dados Scopus foi criada em 2004 e tem como um dos critérios para inclusão de revistas científicas que em suas políticas editoriais incluam a revisão por pares na modalidade duplo cego (Rojas V. e Rivera M., 2011). Entretanto, nem todas as bases possuem critérios claros quanto à modalidade de revisão por pares a ser utilizada pelo periódico para que o mesmo faça parte da coleção. Nos critérios para admissão e permanência de periódicos científicos na Coleção SciELO Brasil (2014), por exemplo, não há exigência de que a modalidade seja duplo cego ou qualquer menção ao tipo de revisão a ser praticada pelo periódico.

Por outro lado, o tema do anonimato está ligado também à confiabilidade das informações. Todos os agentes envolvidos no processo precisam manter o sigilo não só das identidades, mas também das informações. Segundo o European Peer Review Guide (2011) da European Science Foundation, pesquisas sobre revisão por pares indicam que a modalidade simples-cego é a mais utilizada na maioria das organizações. No entanto, afirma o documento, em alguns países escandinavos há legislação que exige total transparência na avaliação quando há financiamento público. 


\section{Procedimentos Metodológicos}

Este trabalho é parte de uma pesquisa voltada para a comparação do sistema de avaliação pelos pares em três países, de natureza exploratória, estando este concentrado na modalidade avaliativa em periódicos científicos. Os países escolhidos foram: Brasil, Espanha e México. A seleção das revistas obedeceu aos critérios de qualidade exigidos nos países, com ênfase nas mais qualificadas, tendo em vista que elas atendem a todos os requisitos necessários para serem contempladas nas principais bases e listas de organismos científicos de renome.

Após a seleção dos periódicos, identificaram-se os editores para envio do questionário, composto de onze questões fechadas e uma aberta e elaborado a partir da Escala Visual Analógica (EVA) para dor (Visual Analogue Scale - VAS), muito utilizada na área médica para aferir a intensidade da dor em pacientes atendidos em hospitais, prontos-socorros, etc. (Martinez; Grassi; Marques, 2011). As questões contempladas pelo questionário buscaram verificar as dificuldades enfrentadas pelos editores na realização das tarefas que compõem a gestão de um periódico científico. Entretanto, neste trabalho a questão explorada é aquela que questionava os editores quanto ao tipo de sistema de avaliação praticado pelo periódico no qual era editor. O instrumento foi enviado em dois momentos: a) no período de 16 a 20 de fevereiro de 2015 para editores brasileiros e para metade do universo de editores espanhóis; e b) no período de 27 de maio a $1^{\circ}$ de junho de 2015 para editores mexicanos e a outra metade dos editores espanhóis.

Convém esclarecer que os periódicos foram selecionados a partir das bases e listas científicas de seus respectivos países. O agrupamento dos periódicos nas quatro áreas do conhecimento foi com base na autodeclaração dos editores científicos quando da resposta ao questionário. O número de periódicos e a distribuição em áreas do conhecimento são expressos a seguir.

1. Brasil: 187 periódicos presentes no Sistema Qualis da CAPES no estrato A1 e A2 em pelo menos uma área do conhecimento, assim distribuídos: 67 das Ciências da Vida, 14 das Ciências Puras, 25 das Ciências Sociais e 81 das Humanidades;

2. Espanha: 189 revistas certificas com o selo de qualidade editorial pela lista da Fundación Española para la Ciencia y Tecnología (FECYT), 
Sistema de revisão por pares na ciência: o caso de revistas científicas do

sendo: 11 revistas de Ciências da Vida, 29 das Ciências Puras, 85 das Ciências Sociais e 66 das Humanidades; e

3. México: 137 revistas constantes Índice de Revistas Mexicanas de Investigación Científica y Tecnológica, com a seguinte distinção: 19 de Ciências da Vida, 32 de Ciências Puras, 50 de Ciências Sociais, 32 de Humanidades e 4 consideradas multidisciplinares.

A pesquisa foi desenvolvida em três etapas. Na primeira foi realizado um estudo a partir da literatura sobre o processo de revisão por pares tendo como enfoque sua importância enquanto mecanismo de certificação do conhecimento científico e reprodução de valores e crenças no campo científico. A segunda etapa consistiu na identificação da população-alvo que foi constituída de editores de periódicos científicos de grande prestígio segundo os critérios das agencias de cada país estudado, seguido da elaboração e aplicação do questionário. A terceira etapa consistiu na análise dos dados mediante um tratamento estatístico descritivo com o intuito de confirmar ou não, nas respostas analisadas, aspectos trazidos à luz pela literatura pertinente.

\section{Resultados}

A taxa de retorno dos questionários enviados foi de $21,4 \%$ para a amostra de editores brasileiros, 24,3\% para editores espanhóis e 31,4\% para editores mexicanos, embora tenha havido semelhança no número de respondentes dos três países participantes da pesquisa (Brasil, 42; Espanha, 46; México, 46). Em relação à composição da amostra de editores brasileiros, predominaram editores de Ciências Sociais e no caso espanhol, editores da área de Ciências da Vida. No caso mexicano há certo equilíbrio entre Ciências da Vida e Ciências Sociais de um lado e Ciências Puras e Humanidades de outro.

A modalidade de revisão por pares que prevaleceu na comparação entre as respostas de editores dos três países foi a duplo cego. Editores de revistas espanholas relataram que em $89,1 \%$ dos periódicos a modalidade mais praticada é a duplo cego, enquanto que no Brasil a taxa para essa modalidade é $81 \%$ e no México, $80,4 \%$. A modalidade simples cego prevaleceu em $19 \%$ das respostas de editores brasileiros e em $17,4 \%$ nas respostas de editores mexicanos. Editores espanhóis responderam que o sistema simples cego só é praticado em $8,7 \%$ das revistas. Os dados também revelaram que em periódicos brasileiros 
que compuseram a amostra, o sistema aberto não é praticado. Mesmo para editores espanhóis e mexicanos a taxa de uso do sistema no processo de revisão por pares foi baixa, de $2 \%$ para ambos os países, conforme se observa no Gráfico 01.

Gráfico 1. Modalidade de revisão praticada em periódicos, por país (percentagens)

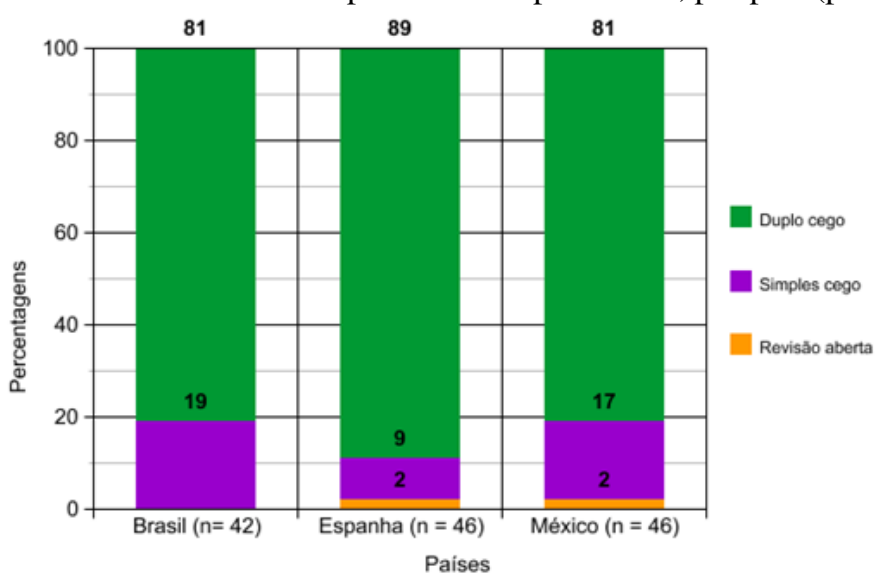

Fonte: dados de pesquisa

A representação acima evidencia a prevalência da modalidade duplo cego praticada pelos periódicos mais importantes nos três países, sendo que na Espanha alcançou $89 \%$ do universo analisado. A modalidade simples cego é pouco utilizado pelas revistas brasileiras, espanholas e mexicanas, com índices de prática entre $9 \%$ à $19 \%$. Chama atenção também que apenas as revistas do Brasil não praticam a revisão aberta em suas avaliações, enquanto que as da Espanha e do México são mais escassas.

O Gráfico 01 sinaliza que as práticas avaliativas das revistas científicas dos três países são semelhantes, tendo em vista os valores informados pelos editores científicos. O cenário apresenta realidades semelhantes no que concerne às atividades editoriais dos periódicos dos três países, mas com sensíveis diferenças e, embora parcial, expressam que o anonimato é a prática avaliativa mais recorrente. Contudo, nota-se que a abertura para a divulgação de revisores e autores poderá ser visualizada em outros contextos e em outros períodos 
Sistema de revisão por pares na ciência: o caso de revistas científicas do Brasil, da Espanha e do México

de tempo. Nesses termos, questiona-se: qual o cenário da revisão pelos pares praticados por esses periódicos em seus países no futuro próximo?

Quanto às áreas do conhecimento e a dimensão das modalidades de revisão por pares, o Gráfico 02 é apresentado a seguir.

Gráfico 2. Áreas do conhecimento e modalidades de revisão por pares (percentagens)

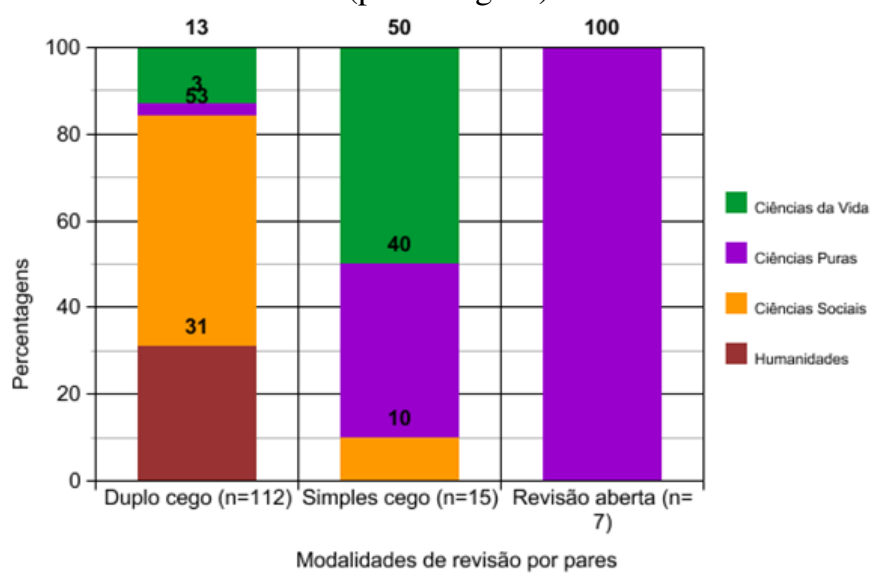

Fonte: dados de pesquisa

O Gráfico 02 ilustra os valores em percentuais da revisão por pares praticada em cada uma das áreas de conhecimento dos periódicos que participaram da pesquisa, com destaque para algumas particularidades:

a) o sistema duplo cego é utilizado por todas as áreas do conhecimento, com predominância nas Ciências Sociais (53\%) e Humanidades (31\%);

b) o sistema simples cego é praticado por três das quatro áreas, sobretudo pelas Ciências da Vida (50\%) e Ciências Puras (40\%); e

c) o sistema de revisão aberta é a modalidade praticada apenas pelas $\mathrm{Ci}$ ências Puras.

A ilustração acima aponta que as revistas da área das Humanidades só utilizam o sistema duplo cego e as Ciências Puras, em sua maioria, a revisão aberta. Verifica-se que, em sua maioria, as revistas das Ciências da Vida se utilizam da revisão simples cego e das Ciências Sociais da revisão duplo 
cego. Percebe-se ainda que os periódicos das Ciências Puras caminham em sentido oposto ao das Humanidades e Ciências Sociais, concentrando-se na divulgação dos envolvidos no processo de avaliação. A configuração do quadro apontado sugerem as seguintes questões:

a) quais as causas que levam os periódicos das Ciências Puras a utilizarem a revisão aberta como modalidade em suas práticas de avaliação?;

b) as justificativas dos periódicos das Ciências Puras são antagônicos aos das Ciências Sociais e Humanidades?; e

c) quais os motivos dos periódicos das Ciências da Vida?

Para discutir sobre as modalidades de revisão por pares praticadas pelos periódicos nos países contemplados pelo estudo, traz-se o Gráfico 03 que apresenta o caso brasileiro.

Gráfico 3. Modalidade de revisão praticada em periódicos brasileiros, por área de conhecimento (percentagens)

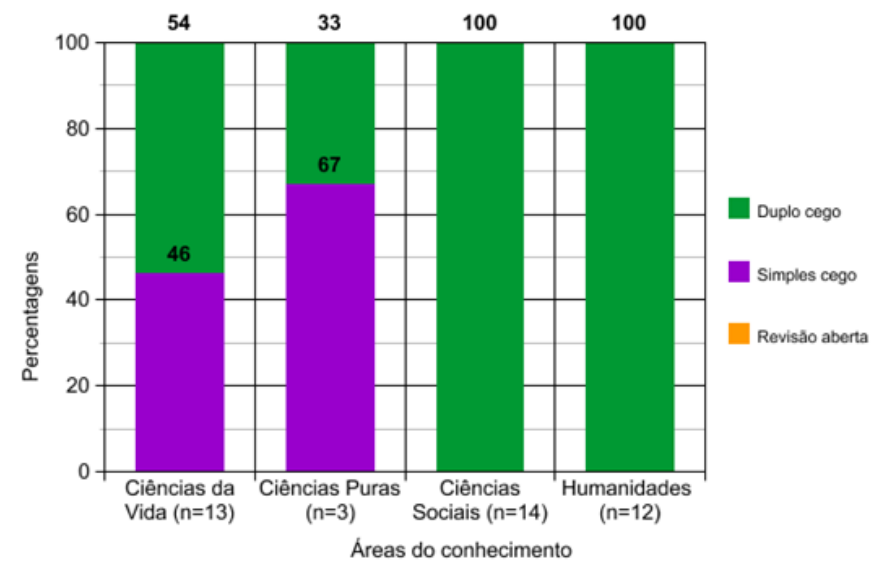

Fonte: dados de pesquisa

A representação gráfica indica que os periódicos brasileiros contemplados neste estudo não praticam a revisão aberta em nenhuma das quatro áreas do conhecimento. Já a revisão duplo cego é a modalidade praticada por todas as áreas, sendo que nas Ciências Sociais e as Humanidades pela totalidade das revistas examinadas. Para as Ciências da Vida, o sistema duplo cego chega 
Sistema de revisão por pares na ciência: o caso de revistas científicas do

a 54\% dos periódicos, destacando sua vitalidade e dividindo espaço com o sistema simples cego, $46 \%$ do total. Por sua vez, a modalidade de revisão duplo cego é menos utilizado pelos periódicos brasileiros das Ciências Puras, com 33\% do total, em detrimento da revisão simples cego com $67 \%$.

O panorama descrito do caso brasileiro aponta que as práticas de avaliação nas revistas científicas estão concentradas no sistema duplo cego, com indícios de abertura expressiva para o simples cego nas Ciências da Vida e Ciências Puras. Por outro lado, as Ciências Sociais e as Humanidades não consideram outra forma de avaliação a não ser o duplo cego, ambas com 100\%. Com isso, questiona-se:

a) quais as razões que levam as revistas brasileiras das Ciências Sociais e das Humanidades a utilizarem o sistema duplo cego como prática de avaliação, em detrimento das outras opções?; e

b) estão as revistas de Ciências da Vida e Ciências Puras caminhando para outras perspectivas de avaliação de originais em que o anonimato não é mais tão importante?

A seguir, apresenta-se o Gráfico 04 que mostra as modalidades de avaliação dos periódicos espanhóis por áreas do conhecimento. 
Gráfico 4. Modalidade de revisão praticada em periódicos espanhóis, por área de conhecimento (percentagens)

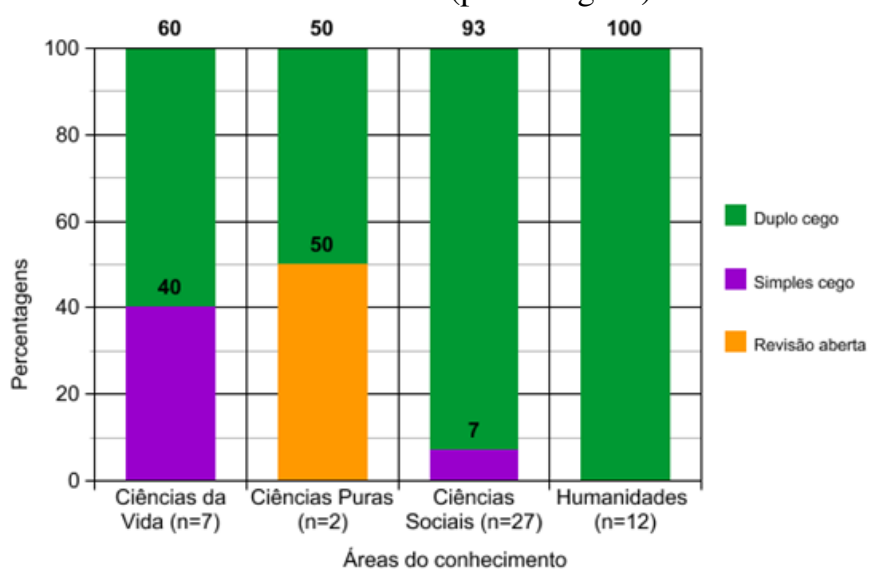

Fonte: dados de pesquisa

A ilustração revela que o sistema duplo cego é a modalidade de avaliação preferida de todas as revistas espanholas nas quatro áreas do conhecimento. O sistema simples cego é contemplado com mais ênfase por periódicos das Ciências da Vida, com $40 \%$ do total, e mais timidamente pelos periódicos das Ciências Sociais, com $8 \%$. Já a revisão aberta é praticada por metade das revistas espanholas das Ciências Puras que compõem o universo estudado.

No caso espanhol, as respostas dos editores de periódicos analisados revelam que as áreas do conhecimento se utilizam apenas de duas formas de avaliação de originais, com exceção das Humanidades, que privilegia o duplo cego. Para as Ciências da Vida e as Ciências Puras, as práticas avaliativas se encontram equilibradas, enquanto que nas Ciências Sociais a distinção entre as duas formas é mais desigual. Do panorama evidenciado, surgem dois questionamentos:

a) quais os motivos que levam os poucos periódicos espanhóis das Ciências Sociais a utilizarem o sistema simples cego como modalidade de avaliação de artigos, tendo em vista que a parte significativa pratica o duplo cego?; 
Sistema de revisão por pares na ciência: o caso de revistas científicas do

b) por que as práticas de avaliação praticadas pelas revistas das Ciências Puras são antagônicas, na medida em que o anonimato é importante para algumas e não para outras?

O Gráfico 05, expresso a seguir, aponta as preferências de avaliação dos periódicos do México nas quatro áreas do conhecimento.

Gráfico 5. Modalidade de revisão por pares praticada em periódicos mexicanos, por área de conhecimento (percentagens)

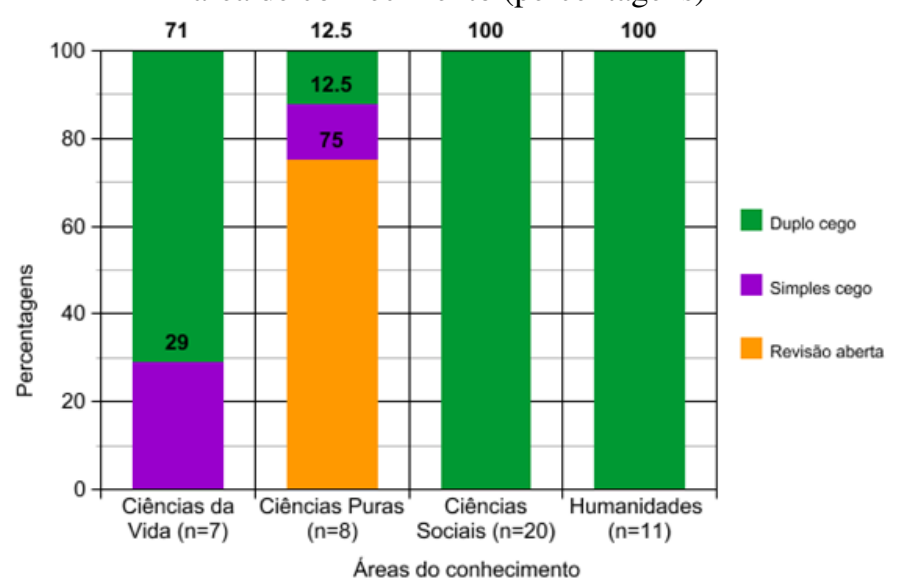

Fonte: dados de pesquisa

O Gráfico 05 sinaliza que os periódicos mexicanos das quatro áreas do conhecimento fazem uso do sistema duplo cego em suas práticas de avaliação, e em números representativos em três áreas. A modalidade simples cego é praticada de forma tímida e por apenas duas áreas do conhecimento: Ciências da Vida e Ciências Puras com 29\% e 12,5\% respectivamente. Menciona-se a exclusividade da prática de avaliação de originais, em que revisores e autores são conhecidos, pelas revistas das Ciências Puras, com 75\% do total da área do conhecimento.

O quadro apresentado acima revela que três áreas do conhecimento não abrem mão do anonimato nas avaliações, sobretudo as Ciências Sociais e as Humanidades, ambas com 100\%; as Ciências da Vida, ainda com práticas de avaliação de simples cego, a modalidade duplo cego é a preferida por mais de $70 \%$ das revistas mexicanas. Cabe registrar também a pluralidade de mo- 
dalidades nas revistas das Ciências Puras do México, que contemplas as três possibilidades, com predominância da revisão aberta. Diante do cenário percebido, surgem as seguintes questões:

a) quais as razões que levam os periódicos do México das Ciências Puras a praticarem a revisão aberta com tanta ênfase?;

b) quais as tendências para os próximos anos quanto à manutenção da modalidade de avaliação para os periódicos mexicanos das Ciências Puras que não praticam a revisão aberta?;

c) os periódicos das Ciências Sociais e das Humanidades do México continuarão a privilegiar o anonimato com forma de revisão por pares?

\section{Considerações finais}

As práticas de avaliação da qualidade do conhecimento científico voltadas às modalidades de revisão por pares em periódicos observadas, neste trabalho, sugerem dois aspectos importantes: a dimensão nacional e o fazer científico das áreas do conhecimento. Embora estejam fortemente relacionados entre si, tais aspectos também se distanciam, pois modos particulares de produção e comunicação da ciência são praticados. Nesse sentido, a revisão por pares que acontece em cada país mostra que o comportamento dos pesquisadores pode estar subordinado tanto à natureza epistemológica da ciência quanto às formas que compreendem a avaliação em periódicos.

A preferência entre o anonimato ou não no processo de avaliação por pares adotado pelos periódicos parece ser o cerne da questão, pois se observou que as áreas tidas como mais flexíveis (soft science) foram aquelas onde esse sistema avaliativo esteve mais presente, mesmo sabendo que o anonimato absoluto pode ser um mito, em algumas circunstâncias de produção e comunicação. Em alguns casos, o estilo, os metadados e a especialidade de um estudo podem relevar facilmente a autoria para o revisor e, dependendo da área do conhecimento, a avaliação pode ser conduzida de muitas formas.

Por outro lado, o anonimato parcial praticado na modalidade simples cego aponta ser um indício de que avaliação da produção científica é utilizada tanto para o reconhecimento dos pares, quanto para a aferição de sua qualidade das contribuições submetidas. Com isso, perpetuam-se os valores estabelecidos em cada campo científico e ainda a reprodução da estrutura que rege a distri- 
Sistema de revisão por pares na ciência: o caso de revistas científicas do

buição de prestígio, moeda fundamental para a consolidação dos cientistas em um determinado campo.

Portanto, afirma-se que os objetivos apresentados foram alcançados, tendo em vista que o panorama proposto foi exibido na perspectiva de um trabalho de natureza exploratória. Entre as principais afirmações sobre os resultados obtidos é de que as formas de avaliação de originais em periódicos científicos costumam variar de área para área de forma mais contundente, enquanto que de país para país de forma sensível e particular. Contudo, em algumas áreas do conhecimento, as práticas de avaliação são bem distintas, trazendo questionamentos para o futuro, sobretudo ao que envolve o anonimato.

\section{Referências}

Botomé, S.P. (2011). Avaliação entre "pares" na ciência e na academia: aspectos clandestinos de um julgamento nem sempre científico, acadêmico ou "de avaliação". Psicologia USP, junho, 22(2): 335-356. Recuperado em 12 de abril de 2015, de http://dx.doi.org

Brown, D. (2006). Scientific communication and the dematerialization of scholarship. Proquest-CSA Discovery Guides. Mar. Recuperado em 14 novembro, 2013, de www.csa.com

Brown, T. (2004). Peer review and the acceptance of new scientific ideas. London: Sense About Science.

Bufrem, L.S. (2014). Faces da produção periódica na Ciência da Informação: o processo de legitimação científica e seus componentes. Informação \& Informação, 19(3): 01-19. Londrina.

Cassella, M. (2010). Social peer-review e scienze umane, ovvero "della qualità nella Repubblica della scienza". JLIS.it, Giugno/June, 1(1): 111-132. Recuperado em 30 janeiro, 2014, de http://dialnet.unirioja.es

Fundación Europea de la Ciencia (2011). European peer review guide integrating policies and practices into coherent procedures. Strasbourg: European Science Foundation. Recuperado em 30 junho 2015, de www.vr.se

Jenal, S.; Vituri, D.W.; Ezaías, G.M.; Silva, L.A. \& Caliri, M.H.L. (2012). O processo de revisão por pares: uma revisão integrativa de literatura. Acta Paulista de Enfermagem, 25(5): 802-808. Recuperado em 16 abril, 2015, de www.scielo.br. 
Martinez, J.E; Grassi, D.C. \& Marques, L.G. (2011). Análise da aplicabilidade de três instrumentos de avaliação de dor em distintas unidades de atendimento: ambulatório, enfermaria e urgência. Revista Brasileira de Reumatologia, 51(4): 304-308. Disponível em: www.scielo.br. Acesso em 09 de maio de 2015.

Mulligan, A.; Hall, L. \& Raphael, E. (2013). Peer Review in a Changing World: An International Study Measuring the Attitudes of Researchers. Journal of the American Society for Information Science and Technology, 64(1): 132-161. Recuperado em 26 de maio de 2015 de http://dx.doi.org.

Ohler, L. (2010). Escrevendo para publicação: questões éticas. Texto \& Contexto Enfermagem, 19(2): 214-216. Recuperado em 10 junho de 2015 de www.redalyc.org

Pavan, C. \& Stumpf, I.R.C. (2009). Avaliação pelos pares nas revistas brasileiras de Ciência da Informação: procedimentos e percepções dos autores. Encontros Bibli, 14(28): 73-92. Florianópolis.

Ranalli, B. (2011). A prehistory of peer review: religious blueprints from the hartlib circle. Spontaneous Generations: A Journal for the History and Philosophy of Science, 5(1): 12-18. Recuperado em 15 de março de 2015 de http://dx.doi.org

Rojas, V.M.A. \& Rivera, M.S. (2011). Guía de Buenas Prácticas para Revistas Académicas de Acceso Abierto. ONG Derechos Digitales. Recuperado em 25 de maio de 2015 de www.derechosdigitales.org

SCIELO BRASIL. (2014). Critérios SciELO Brasil: critérios, política e procedimentos para a admissão e a permanência de periódicos científicos na coleção SciELO Brasil. São Paulo. Versão de setembro de 2014. Recuperado em 1 de julho de 2015 de www.scielo.br

SMC. (2003). Peer review in a nutshell. Recuperado el 30 de 06 de 2015, de Science Media Centre: www.sciencemediacentre.org

Stumpf, I.R. (2005). Avaliação de originais nas revistas científicas: uma trajetória em busca do acerto. In S.M. Ferreira \& M.d. Targino, Preparação de revistas científicas: teoria e prática (pp. 103-120). São Paulo: Reichmann \& Autores.

Souza, R.F. de (2004). Áreas do conhecimento. Datagramazero, 5(2), sem paginação. 